\title{
LIST OF REFEREES
}

The editorial committee wishes to thank the referees.

- Ian Dawson

World Agroforestry Centre, Kenya

- Ann Degrande

World Agroforestry Centre (ICRAF), Cameroon

- Tom De Herdt

Instituut voor Ontwikkelingsbeleid en -beheer (IOB), University of Antwerp, Belgium

- Johan De Smedt

Pelckmans Uitgeverij, Belgium

- Peter Gichangi

International Centre for Reproductive Health, Kenya

- Richard Lumbika Nlandu

Centre des Droits de l'Homme, Université Kongo, République Démocratique du Congo

- Ousseynou Ndoye

Food and Agriculture Organization of the United Nations, Gabon

- Wouter van Beek

African Studies Centre Leiden, The Netherlands

- Christophe Van der Beken

Institute of Federalism and Legal Studies, Ethiopian Civil Service University, Ethiopia

- Patrick Van Damme

Laboratory of Tropical and Subtropical Agriculture and Ethnobotany, Ghent University, Belgium \& Institute of Tropics and Subtropics, Czech University of Life Sciences, Czech Republic

- Annelies Verdoolaege

Department of Languages and Cultures, Ghent University, Belgium

- John C. Weber

World Agroforestry Centre, West and Central Africa, Mali 